\title{
Heymann, Britta, Ernst Melsheimer (1897-1960), Eine juristische Karriere in verschiedenen staatlichen Systemen
}

Marie-Bénédicte Vincent

\section{OpenEdition}

Édition électronique

URL : http://journals.openedition.org/ifha/1716

DOI : 10.4000/ifha. 1716

ISSN : 2198-8943

Éditeur

IFRA - Institut franco-allemand (sciences historiques et sociales)

Référence électronique

Marie-Bénédicte Vincent, « Heymann, Britta, Ernst Melsheimer (1897-1960), Eine juristische Karriere in verschiedenen staatlichen Systemen », Revue de l'IFHA [En ligne], Date de recension, mis en ligne le 01 janvier 2008, consulté le 22 septembre 2020. URL : http://journals.openedition.org/ifha/1716 ; DOI https://doi.org/10.4000/ifha. 1716

Ce document a été généré automatiquement le 22 septembre 2020.

(CIFHA 


\title{
Heymann, Britta, Ernst Melsheimer (1897-1960), Eine juristische Karriere in verschiedenen staatlichen Systemen
}

\author{
Marie-Bénédicte Vincent
}

1 Ernst Melsheimer fut incontestablement un de ces furchtbare Juristen, devenus aujourd'hui lieux de mémoire (Michael Stolleis dans les Deutsche Erinnerungsorte, vol. 2, München : Beck, 2001). La particularité du parcours de Melsheimer (1897-1960) réside dans son étonnant maintien en poste à un niveau élevé des instances judiciaires, de la République de Weimar, du Troisième Reich et de la RDA. Qu'est ce qui a rendu possible cette carrière exceptionnelle?

2 Melsheimer est né dans un milieu petit-bourgeois de la Sarre et s'est engagé lors de la Première Guerre mondiale. Blessé en 1915, il entreprend alors des études de droit. Il n'a que 21 ans lorsqu'est proclamée la République de Weimar. Directement appelé au ministère prussien de la Justice en 1921 en raison de ses bonnes notes au second examen d'État, il y reste seize ans et survit donc à la césure de 1933. C'est en soi un fait très étonnant. En effet, Melsheimer n'a pas caché son appartenance au SPD de 1928 à novembre 1932, ni à la Reichsbanner (mouvement républicain d'anciens combattants) de 1928 à 1933, ni au Republikanischer Richterbund, une association de juges républicains créée au début de la République pour faire contrepoids au sein d'une magistrature majoritairement conservatrice. Du fait de ces différentes allégeances, Melsheimer était tout sauf un « apolitique».

3 Or il est resté en poste sous le Troisième Reich, même après la loi sur la restauration de la fonction publique professionnelle du 11 avril 1933 épurant le service de l'État. Le critère de la compétence juridique, très valorisé dans la tradition prussienne, a primé sur ses convictions de "gauche ", même après la fusion en 1935 du ministère prussien avec le ministère du Reich. En 1937, Melsheimer est nommé magistrat au Kammergericht jusqu'à la fin de la Seconde Guerre mondiale : il s'agit là encore d'un poste prestigieux, même si l'intéressé décrira ensuite cette mutation comme une brimade. Melsheimer a certes pour lui de n'avoir jamais adhéré au NSDAP, mais il est 
devenu membre d'une organisation satellite, le NS-Rechtswahrerbund : cette " appartenance-alibi » ne le préserve pas de la compromission selon l'auteur. Du reste, Melsheimer n'a pas mené de résistance active, de son aveu même. Un Mitläufer donc?

4 À la chute du nazisme, Melsheimer adhère au KPD dès sa création en juin 1945. Ce choix étonne à nouveau : pourquoi pas le SPD ? (par dégoût de ce parti, après le coup de Prusse du 20 juillet 1932, ou par opportunisme ?). Curieusement, Melsheimer a tenté d'être embauché dans le secteur américain tout en menant parallèlement des démarches auprès des Soviétiques. Il est finalement nommé procureur dans le district de Friedenau à Berlin le 16 mai 1945. Il acquiert une renommée lors de l'un des premiers procès d'après-guerre et est promu chef du service de la législation au sein de la Deutsche Zentrale Justizverwaltung créée le 27 juillet 1945, où il jouit de la confiance des Soviétiques. Melsheimer s'est intensivement impliqué dans la mise en place des instances judiciaires de la zone, ce qui explique sa nomination en 1949 comme procureur général de la RDA. À ce titre, il joue un rôle de premier plan dans une vingtaine de "procès-vitrines » du régime. En réalité, sa marge de manœuvre était étroite et il recevait ses instructions du SED - dont il était membre - pour toutes les questions politiques.

5 Ce parcours soulève évidemment nombre de problèmes, qui renvoient aux grandes questions de l'histoire allemande contemporaine. Comment un républicain convaincu a-t-il pu survivre au changement de régime en 1933 ? Comment un fonctionnaire de premier plan du Troisième Reich a-t-il pu échapper à la dénazification sévère de la zone soviétique ? Et comment un ancien social-démocrate a-t-il pu tirer son épingle du jeu lors des épurations du SED?

6 Malheureusement, ce livre reste surtout descriptif. Même pour la partie la plus développée sur l'après-1945, le contexte se réduit à une histoire interne des instances judiciaires. L'auteur, juriste et non historien, n'utilise pas la bibliographie sur l'histoire sociale des fonctionnaires et des juristes. Il manque une réflexion plus générale sur le sens du service de l'État au sein du Berufsbeamtentum qui permettrait de mettre en perspective ce parcours. Si le livre pointe bien les paradoxes du personnage, la conclusion reste très prudente et l'auteur peine à répondre à la question posée en ouverture : « Qui était vraiment Ernst Melsheimer?»

Marie-Bénédicte Vincent (Université d'Angers) 